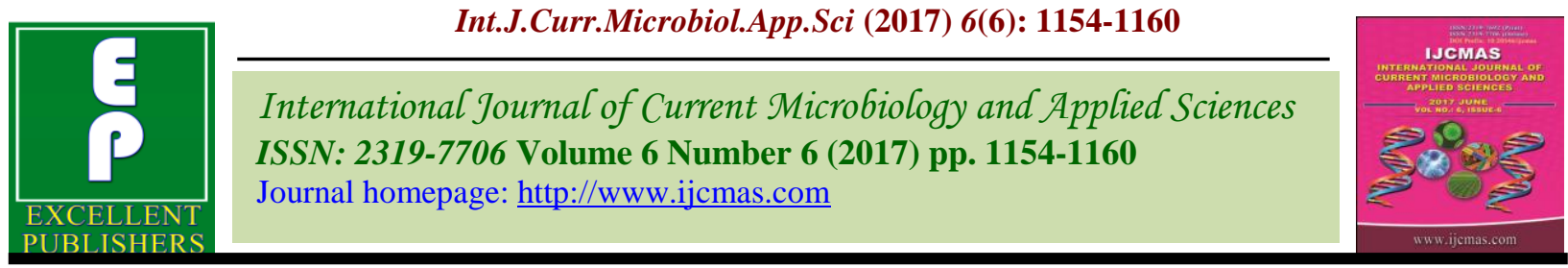

Original Research Article https://doi.org/10.20546/ijcmas.2017.606.133

\title{
Growth of Rice Blast Fungus Pyricularia oryzae (Cav.) on Different Solid and Liquid Media
}

\author{
Akhilesh Kumar Kulmitra*, Neha Sahu, Mukesh Kumar Sahu, Roshan Kumar, \\ T. Kushram and V.B. Sanath Kumar
}

Department of Plant Pathology, University of Agricultural Sciences, Bangalore-560065, India *Corresponding author

\section{A B S T R A C T}

The study was conducted to describe the cultural characteristics such as colour and texture of the leaf blast pathogen Pyricularia oryzae (Cav.) on different solid media

\begin{tabular}{|l|}
\hline Key w or d s \\
Cultural \\
characteristics, \\
Mycelial growth, \\
Pyricularia oryzae. \\
\hline Article Info \\
\hline $\begin{array}{l}\text { Accepted: } \\
17 \text { May } 2017 \\
\text { Available Online: } \\
\text { 10 June } 2017\end{array}$ \\
\hline
\end{tabular}
viz., potato dextrose agar, potato carrot agar, Kirchoff's, medium, Richard's medium, Sabourad's medium, Takahashii's medium, rice leaf extract agar and oat meal agar and liquid media viz., potato dextrose broth, potato carrot broth, Kirchoff's broth, Richard's broth, Sabourad's dextrose broth, Takahashii's broth and rice leaf extract broth. Among all the solid media the highest mean mycelial growth of the fungus Pyricularia oryzae (Cav.) was recorded on oat meal agar $(77.6 \mathrm{~mm})$ followed by rice leaf extract $(75.9 \mathrm{~mm})$ and least mean mycelial growth of the $P$. oryzae $(\mathrm{Cav}$.$) on$ Sabourad's media $(44.7 \mathrm{~mm})$ followed by Takahashii's media $(52.5 \mathrm{~mm})$. The maximum mean dry mycelial weight of fungus recorded in Kirchoff's broth (211.56mg) followed by Richard's broth $(206.3 \mathrm{mg})$ and the least mean dry mycelial weight of fungus recorded in Takahashii's broth $(178.0 \mathrm{mg})$ followed by Sabourad's broth $(179.7 \mathrm{mg})$. In general, among all solid media the oat meal agar media and among all liquid media the Kirchoff's broth is more appropriate for cultural study of rice blast fungus $P$. oryzae (Cav.).

\section{Introduction}

Rice is a member of the grass family (Poaceae). There are more than 10,000 species of grasses distributed among 600 genera. Grasses occur worldwide in a variety of habitats. Rice is the most important food crop of India covering about one-fourth of the total cropped area and providing food to about half of the Indian population. This is the staple food of the people living in the eastern and the southern parts of the country, particularly in the areas having over $150 \mathrm{~cm}$ annual rainfall. There are about 10,000 varieties of rice in the world out of which about 4,000 are grown in India. They are important source of forage for herbivorous animals. It is spectacularly diverse, both in the way it is grown and how it is used by humans. Rice is unique because it can grow in wet environments that other crops cannot survive in.

Such wet environments are abundant across Asia. Rice is life for thousands of millions of people. In Asia alone, more than 2,000 
million people obtain 60 to 70 per cent of their calories from rice and its products.

Recognizing the importance of this crop, the United Nations General Assembly declared 2004 as the "International Year of Rice" (IYR). The theme of IYR - "Rice is life" reflects the importance of rice as a primary food source, and is drawn from an understanding that rice based systems are essential for food security, poverty alleviation and improved livelihood.

The world's estimated rice production is 496.0 million metric tons during 2016 (Anon, 2016). India is the largest rice growing country accounting for about one third of the world acreage under the crop. In India's annual rice production is 103.6 million tons during 2016 (Anon, 2016). Rice is grown throughout India in all the states. The major rice growing states of India are West Bengal, Uttar Pradesh, Bihar, Madhya Pradesh, Orissa, Andhra Pradesh, Karnataka and Chhattisgarh.

Rice suffers from many diseases caused by fungi, bacteria, viruses, phytoplasma, nematodes and other non-parasitic disorders. Among the fungal diseases, blast is considered as a major threat to rice production because of its wide spread distribution and its destructiveness under favourable conditions. The Commonwealth Mycological Institute has recorded its presence from 85 countries throughout the world. Paddy blast is generally considered as the principal disease of rice and is caused by a fungus belonging to the Ascomycete Pyricularia oryzae Cavara (teleomorph= Magnaporthe grisea (Hebert) Barr Comb nov.). Losses due to the blast disease may range up to 90 per cent depending upon the component of the plant infected. $M$. grisea infects above ground parts of the plant, but neck blast and the panicle blast are the most damaging phases of the disease and have been shown to significantly reduce yield, grain weight and milling quality. The pathogen may infect all the above ground parts of a rice plant at different growth stages viz., leaf, collar, node, internodes, base or neck and other parts of the panicle and sometimes the leaf sheath. A typical blast lesion on a rice leaf is gray at the centre, has a dark border and it is spindle-shaped.

\section{Materials and Methods}

\section{Effect of different media on the growth of P. oryzae (Cav.)}

Culture discs of pathogen $(5 \mathrm{~mm})$ was inoculated separately on different media and incubated at $28 \pm 1^{\circ} \mathrm{C}$ for 15 days. The cultural characters and the colony diameter $(\mathrm{mm})$ on each medium were recorded.

Fifteen $\mathrm{ml}$ of each medium (Table 1) was poured into each of sterilized petriplates. Inoculation was made by transferring the five $\mathrm{mm}$ disk of mycelia mat, taken from the periphery of ten days old culture of each seven isolates. Each treatment was replicated thrice. The plates were incubated at $28 \pm 1^{\circ} \mathrm{C}$. observation of colony growth was taken when the maximum growth was attained in any one of the media tested. Other cultural characters viz., rate of growth, type of margin, colony colour and sporulation were also recorded. The pathogen was multiplied by transferring a loop full of the stock culture to $250 \mathrm{ml}$ of potato dextrose broth taken in a $1000 \mathrm{ml}$ flask. The inoculated flask was incubated at $28 \pm 10 \mathrm{C}$ for fourteen days. The fungal culture growing on broth was passed through double layered muslin cloth. The concentration of spore suspension was adjusted to 50 spores/microscopic field by adding sterilized distilled water. The spore suspension was collected separately in an atomizer and incubated on to the foliage of 20 days old rice (3-4 leaf stage) seedlings of rice. The seedlings after spray inoculation were kept in green house condition with water sprayed 
regularly both during morning and evening hours to maintain relative humidity and pots were covered with polythene bags. After 48 hours, the polythene bags were removed. Periodical observations were made for the development of typical blast symptom on the inoculated plants. The pathogen from typical blast symptom was re-isolated and compared with the original culture as well as published literature to confirm the identity of the pathogen.

\section{Maintenance of culture}

All the seven isolates of $P$. oryzae were maintained on PDA slants at 40C in the refrigerator and subculture periodically at an interval of 30 days during the course of this study.

\section{Proving the pathogenicity}

Seeds of rice from disease free plants were surface sterilized with 0.1 per cent sodium hypochlorite for two minute and sown in pots containing sterilized soil in order to raise healthy seedlings.

\section{Results and Discussion}

\section{Growth of $P$. oryzae on different solid media}

The experiment was conducted as detailed in 'material and methods' to acertain the period when the maximum growth of the fungus could occur Among all the solid media the highest mean mycelial growth of the fungus Pyricularia oryzae (Cav.) was recorded on oat meal agar $(77.6 \mathrm{~mm})$ followed by rice leaf extract $(75.9 \mathrm{~mm})$ and least mean mycelial growth of the $P$. oryzae (Cav.) on Sabourad's media $(44.7 \mathrm{~mm})$ followed by Takahashii's media (52.5mm) (Table 2, Fig. 1).

\section{Growth of $P$. oryzae on different liquid media}

The experiment was conducted to find out the best liquid medium for mycelial growth of the fungus $P$. oryzae. The average mycelial weight of the fungus after 15 days of incubation was taken. The results (Table 3, Fig. 2) indicated that, maximum dry mycelial weight of fungus was obtained in Richard's broth $(284.66 \mathrm{mg}$ ) of isolate 4 followed by Kirchoff's broth $(283.33 \mathrm{mg})$ of isolate 4 and Rice leaf extract broth $(265 \mathrm{mg})$ of isolate 4 .

The least mycelial dry weight of the fungus was recorded in Sabourad's broth (120.22 $\mathrm{mg}$ ) of isolate 2 followed by Takahashii's broth (122 mg) of isolate 3 .

The maximum mean dry mycelial weight of fungus recorded in Kirchoff's broth for all isolates $(211.56 \mathrm{mg})$ followed by Richard's broth $(206.36 \mathrm{mg}$ ) and the least mean dry mycelial weight of fungus recorded in Takahashii's broth $(178.01 \mathrm{mg})$ followed by Sabourad's broth (179.77mg).

Table.1 List of media used to study the growth characters of Pyricularia oryzae

\begin{tabular}{|c|l|l|l|}
\hline Sl. No. & \multicolumn{1}{|c|}{ Solid media } & \multicolumn{1}{c|}{ Liquid media } & \multicolumn{1}{c|}{ Type of media } \\
\hline 1 & Potato dextrose agar (PDA) & Potato dextrose broth & Semi-synthetic \\
\hline 2 & Potato carrot agar (PCA) & Potato carrot broth & Semi-synthetic \\
\hline 3 & Kirchoff's medium & Kirchoff's broth & Synthetic \\
\hline 4 & Richard's medium & Richard's broth & Synthetic \\
\hline 5 & Sabourad's dextrose agar & Sabourad's dextrose broth & Synthetic \\
\hline 6 & Takahashii's medium & Takahashii's broth & Synthetic \\
\hline 7 & Rice leaf extract medium & Rice leaf extract broth & Semi-synthetic \\
\hline 8 & Oat meal agar (OMA) & - & Synthetic \\
\hline
\end{tabular}


Table.2 Growth (mm) of seven isolates of $P$. oryzae on eight solid media after 14 days of incubation

\begin{tabular}{|c|c|c|c|c|c|c|c|c|c|}
\hline \multirow{3}{*}{ Treatment } & \multirow{3}{*}{ Media } & \multicolumn{7}{|c|}{ Isolates } & \multirow{3}{*}{$\begin{array}{l}\text { Mean } \\
(\mathrm{mm})\end{array}$} \\
\hline & & \multicolumn{7}{|c|}{ Growth (mm) } & \\
\hline & & $\mathbf{I}_{1}$ & $\mathbf{I}_{2}$ & $\mathbf{I}_{3}$ & $\mathbf{I}_{4}$ & $\mathbf{I}_{5}$ & $I_{6}$ & $\mathbf{I}_{7}$ & \\
\hline $\mathrm{T} 1$ & Potato dextrose agar & 85.0 & 90.0 & 65.0 & 85.0 & 90.0 & 61.3 & 23.2 & 71.4 \\
\hline $\mathrm{T} 2$ & Potato carrot agar & 86.0 & 76.0 & 66.0 & 90.0 & 83.0 & 51.3 & 21.2 & 67.6 \\
\hline $\mathrm{T} 3$ & Kirchoff's media & 90.0 & 75.0 & 83.0 & 83.0 & 86.0 & 65.6 & 25.5 & 77 \\
\hline $\mathrm{T} 4$ & Richard's media & 90.0 & 74.0 & 85.0 & 53.5 & 53.5 & 53.5 & 25.5 & 62.1 \\
\hline T5 & Sabourad's media & 89.0 & 72.0 & 25.0 & 25.1 & 25.2 & 53.5 & 23.2 & 44.7 \\
\hline T6 & Takahashii's media & 86.0 & 71.0 & 31.0 & 35.2 & 74.9 & 45.2 & 24.4 & 52.5 \\
\hline T7 & Rice leaf extract & 90.0 & 71.0 & 87.0 & 77.0 & 87.2 & 90.0 & 29.6 & 75.9 \\
\hline $\mathrm{T} 8$ & Oat meal agar & 85.0 & 87.0 & 90.0 & 74.0 & 89.5 & 90.0 & 28.1 & 77.6 \\
\hline \multirow{2}{*}{\multicolumn{2}{|c|}{ Mean }} & 87.6 & 77 & 66.5 & 65.3 & 73.6 & 63.8 & 25.1 & \\
\hline & & \multicolumn{2}{|c|}{ Media } & \multicolumn{2}{|c|}{ Isolates } & \multicolumn{2}{|c|}{ Media X Isolates } & & \\
\hline \multicolumn{2}{|l|}{ Sem \pm} & \multicolumn{2}{|c|}{0.23} & \multicolumn{2}{|c|}{0.23} & \multicolumn{2}{|c|}{0.92} & & \\
\hline \multicolumn{2}{|l|}{ CD at $1 \%$} & \multicolumn{2}{|c|}{0.57} & \multicolumn{2}{|c|}{0.57} & \multicolumn{2}{|c|}{2.90} & & \\
\hline \multicolumn{2}{|l|}{ CV \% } & \multicolumn{8}{|c|}{2.42} \\
\hline
\end{tabular}

Table.3 Dry mycelial weight (mg) of the seven isolates of P. oryzae in seven liquid media after 14 days of incubation

\begin{tabular}{|c|c|c|c|c|c|c|c|c|c|}
\hline \multirow{3}{*}{ Sl. No. } & \multirow{3}{*}{ Media } & \multicolumn{8}{|c|}{ Mean dry mycelial weight (mg) } \\
\hline & & \multicolumn{8}{|c|}{ Isolates } \\
\hline & & $\mathbf{I}_{1}$ & $\mathbf{I}_{2}$ & $\mathbf{I}_{3}$ & $\mathbf{I}_{4}$ & $\mathbf{I}_{5}$ & $I_{6}$ & $\mathbf{I}_{7}$ & Mean (mg) \\
\hline 1 & Potato dextrose broth & 189.00 & 137.33 & 160.00 & 282.33 & 196.22 & 224.33 & 196.22 & 196.80 \\
\hline 2 & Potato carrot broth & 185.66 & 131.00 & 152.00 & 258.00 & 186.27 & 216.33 & 195.55 & 189.25 \\
\hline 3 & Kirchoff's broth & 208.00 & 144.00 & 170.22 & 283.33 & 212.99 & 250.00 & 212.38 & 211.56 \\
\hline 4 & Richard's broth & 210.44 & 138.66 & 163.00 & 284.66 & 198.22 & 246.55 & 202.99 & 206.36 \\
\hline 5 & Sabourad's broth & 185.11 & 120.22 & 145.00 & 222.66 & 182.55 & 218.66 & 184.22 & 179.77 \\
\hline 6 & Takahashii's broth & 192.55 & 132.55 & 122.00 & 226.33 & 179.33 & 214.00 & 179.33 & 178.01 \\
\hline \multirow[t]{6}{*}{7} & Rice leaf extract broth & 204.55 & 138.66 & 148.55 & 265.00 & 187.66 & 220.00 & 186.27 & 192.95 \\
\hline & Mean & 196.47 & 134.63 & 151.53 & 260.33 & 191.89 & 227.12 & 193.85 & \\
\hline & & \multicolumn{2}{|c|}{ Media } & \multicolumn{2}{|c|}{$\begin{array}{c}\text { Isolates } \\
\end{array}$} & \multicolumn{2}{|c|}{ Media X Isolates } & & \\
\hline & SEm \pm & \multicolumn{2}{|c|}{0.19} & \multicolumn{2}{|c|}{0.19} & \multicolumn{2}{|c|}{0.51} & & \\
\hline & C.D at $1 \%$ & \multicolumn{2}{|c|}{0.54} & & & \multicolumn{2}{|c|}{1.43} & & \\
\hline & CV \% & \multicolumn{8}{|c|}{2.14} \\
\hline
\end{tabular}


Fig.1 Growth of rice blast fungus $P$. oryzae on different solid media

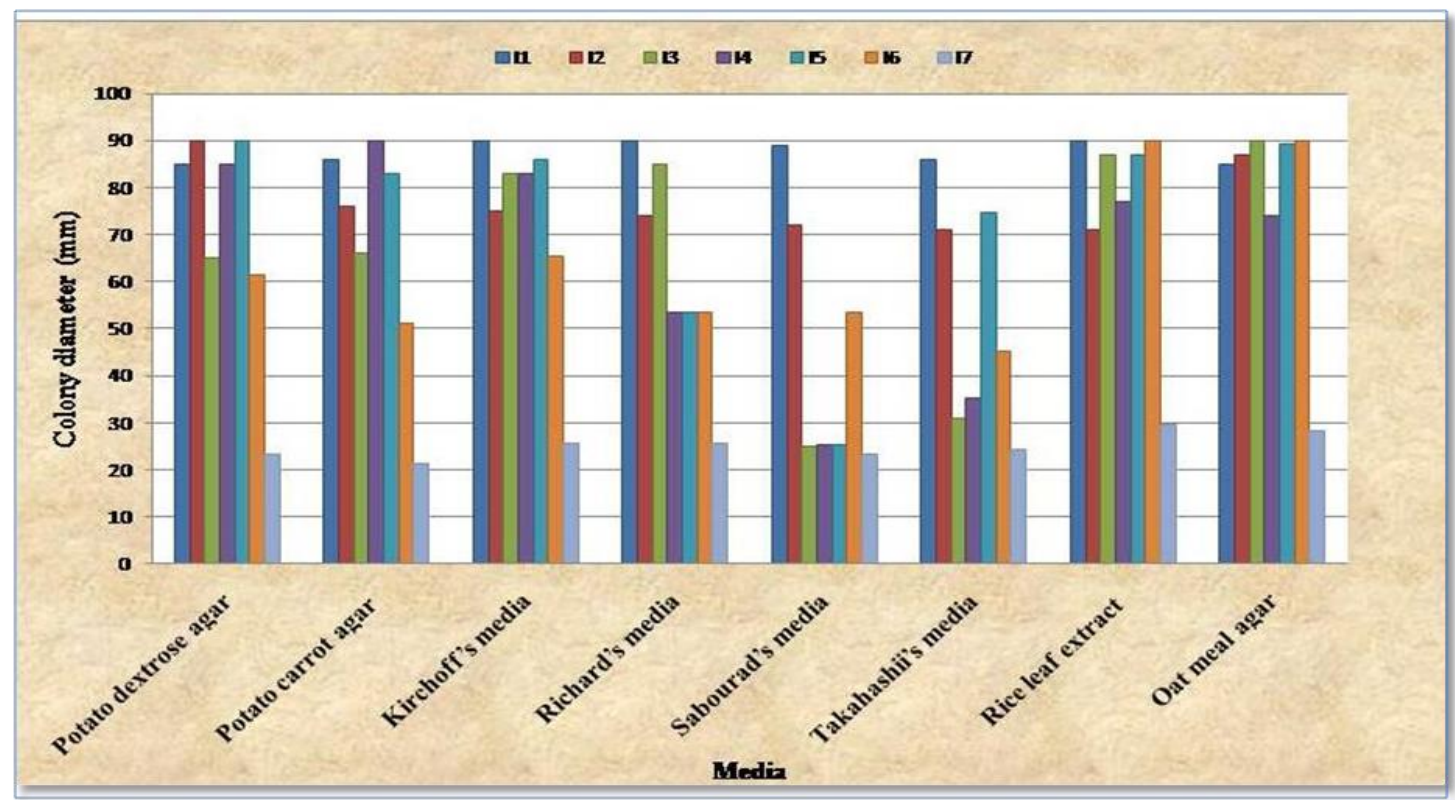

Fig.2 Growth of $P$. oryzae on different liquid media

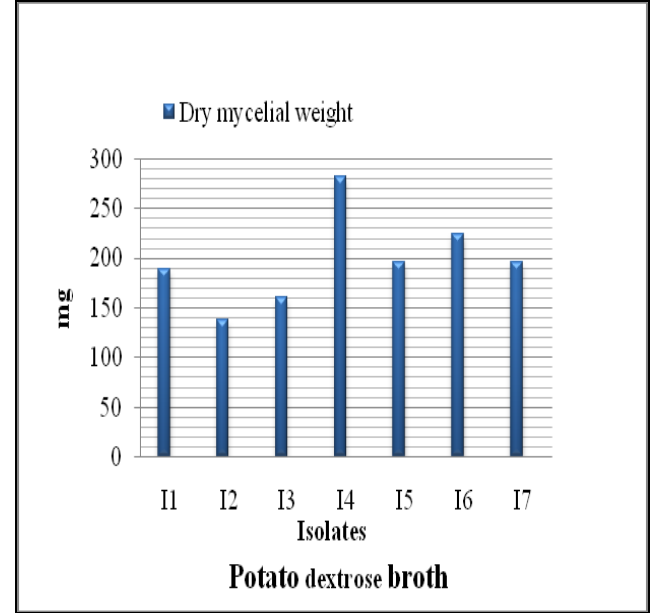

a Growth on Potato dextrose broth

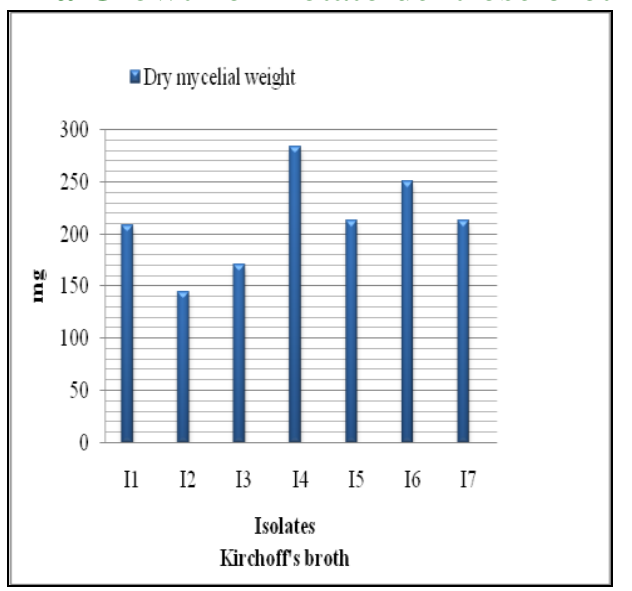

c Growth on Kirchoff's broth

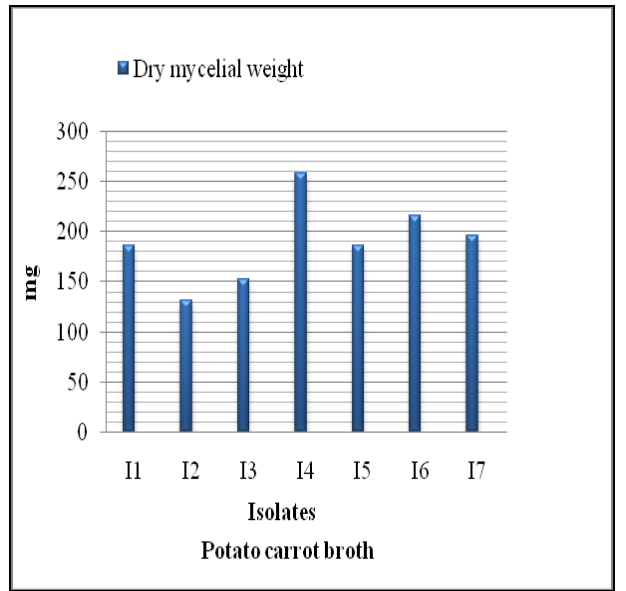

b Growth on Potato carrot broth

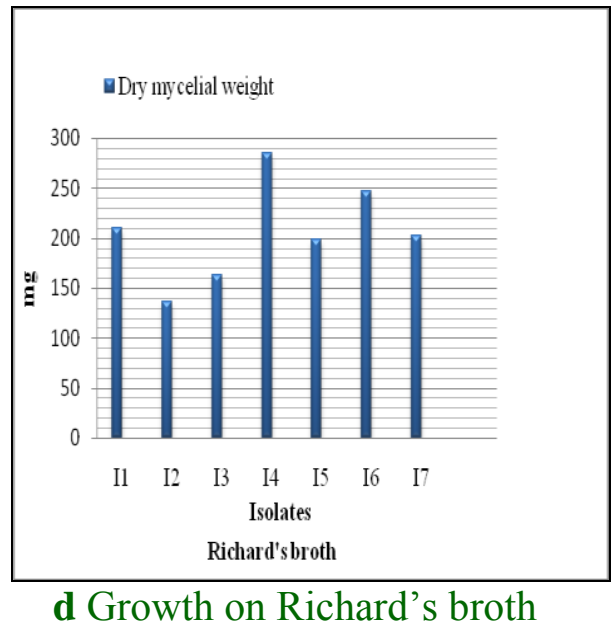




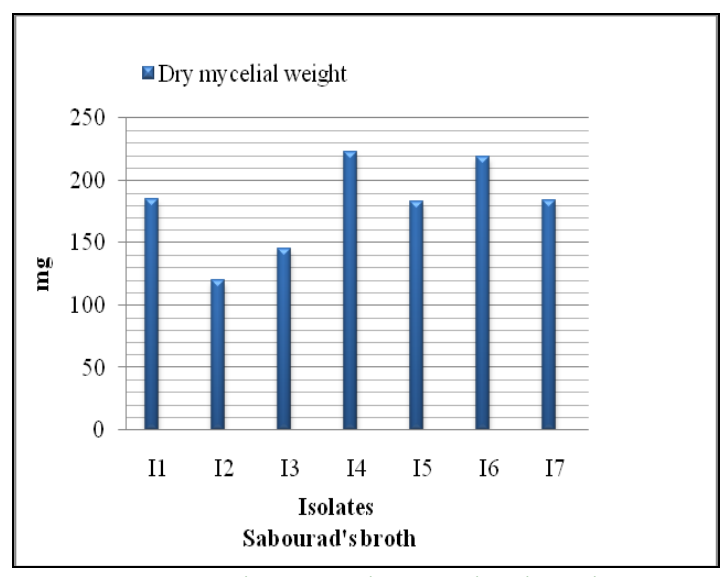

e Growth on Sabourad's broth

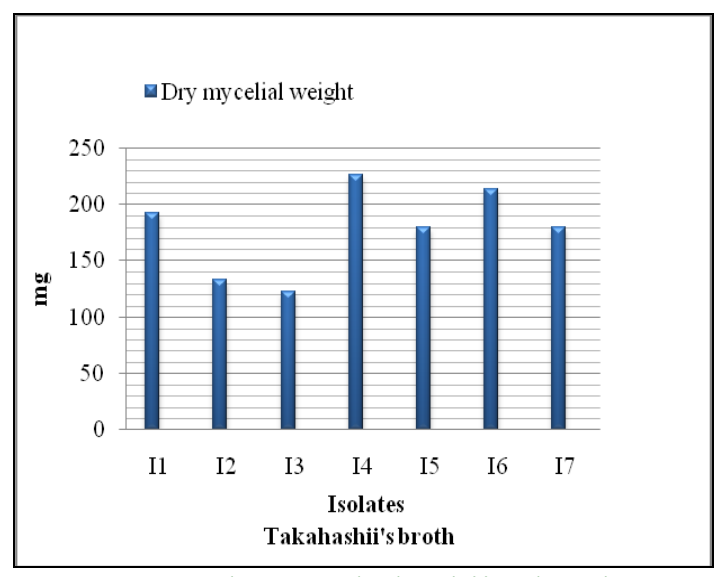

f Growth on Takahashii's broth

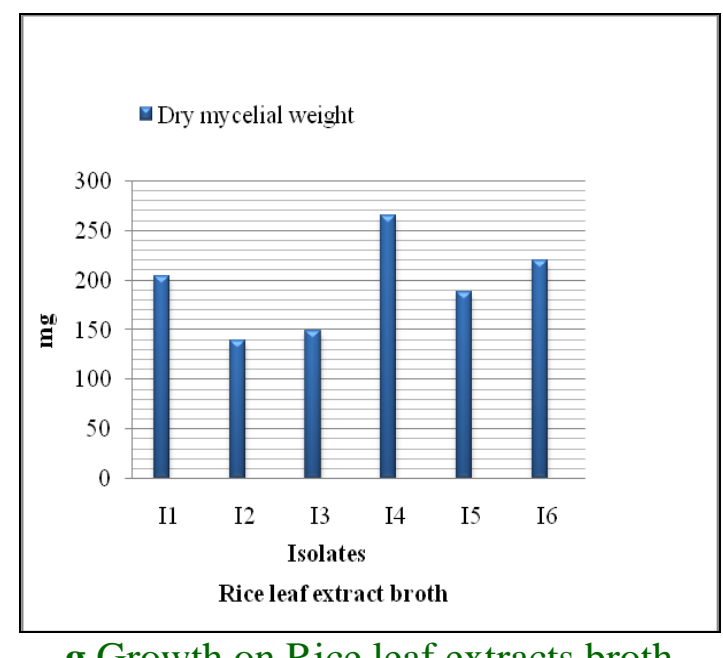

g Growth on Rice leaf extracts broth

Morphological and cultural studies were carried to find out the variation for the growth and sporulation of isolates. Cultural characters of each of the isolates studied on eight different solid media at room temperature 280C showed the variation among the isolates of $P$. oryzae.

Morphological characters viz., size and shape of conidia were studied for identification of the fungus. Conidia were pyriform, almost hyaline to pale olive, 2-septate and 3 celled. The shape, size, septation and colour characters are in agreement with those described by Nishikado (1926) and Mijan Hossain (2000).

Cultural characteristics studied on different media showed the variation among seven isolates of $P$. oryzae with respect to colony characters like type of growth, colour of colony and colony margin (Ou, 1985). Colour varied from grayish black to dark jet black colour, smooth to irregular margin, medium to good growth of the pathogen was observed.

These seven isolates exhibited considerable variation in colony type and colour when grown on different nutrient media. Isolate 1, 4 and 5 developed slightly grayish white colonies on PDA medium while isolate 2, 3, 6 and 7 developed white colonies. In potato carrot agar the isolate 1, 6 and 7 developed dark grayish colonies while 1, 2, 3 and 5 developed grayish white colonies.

In Kirchoff's medium all seven isolates developed dark grayish to white colonies. In Richard's and Sabourad's dextrose medium isolate 6 developed black colour colony while 
other isolates developed slightly grayish white colonies. In Takahashii's medium all isolates developed creamy white colour colonies. In rice leaf extract medium isolate 6 developed white colonies while other isolates developed dark grayish colour colonies. In oat meal agar isolate 1 and 4 developed black colour colonies while other isolates developed white colour colonies (Onofeghara et al., 1973). Unlike the growth on solid media the isolates exhibited considerable differences in their growth when grown in liquid media. In general, isolate 6 and 4 exhibited good growth and 2 and 3 had poor growth, while isolate 1,7 and 5 were intermediates. The mean dry mycelial weight of the isolates was 196.80, 189.25, 211.56, 206.36, $179.77,178.01$ and $192.95 \mathrm{mg}$ in case of isolates 1, 2, 3, 4, 5, 6 and 7 respectively. There have been several reports regarding such variation in growth rate among isolates of a pathogen. Simulated observations have been recorded by Kulkarni (1973) and Onofeghara et al., (1973).

\section{Acknowledgement}

The author wishes to thank Professor V.B. Sanath Kumar, University of Agricultural Sciences, Bangalore, for his sustained interest in this work and the preparation of this paper. The award of ICAR Junior fellowship to the author is also gratefully acknowledged.

\section{References}

Anonymous. 2016. Statistical database. www.fao.org.

Kulkarni, S. 1973. Studies on the blast diseases of the Eleusine coracana (L.) Gaertn. In
Mysore state. M.Sc. (Agri) Thesis, U.A.S., Bangalore, India, pp. 104.

Mijan Hossain, M.D. 2000. Studies on blast disease of rice caused by Pyricularia grisea (cooke) Sacc. In upland area. M.Sc. Thesis, Univ. Agric. Sci., Dharwad, pp. 52-53.

Netam, R.S., Bahadur, A.N., Tiwari, R.K.S. and Tiwari, U. 2013. Effect of different culture Media, carbon source, nitrogen Source, temperature and $\mathrm{pH}$, level on the growth and sporulation of Pyricularia grisea isolate from finger millet. Res. J. Agric. Sci., 4(1): 83-86.

Nishikado, Y. 1926. Studies on rice blast disease. Japanese J. Botany, 3: 239-244.

Onofeghara, F.A., Kaporia, R.G. and Ademokuba, D.O. 1973. Studies on Pyricularia oryzae Lav. in Sierralaone morphological and physiological variability of some isolates. Annals of Bot., 37: 193-202.

Ou, S.H. 1985. Rice Diseases (2nd edn). CABI Publishing, Wallingford, UK. pp. 380. ISBN 0851985459.

Srivastava, R.K., Bhatt, R.P., Bandyopadhyay, B.B. and Kumar, J. 2009. Effect of media on growth, sporulation and production of perithecia of blast pathogen Pyricularia grisea, Res. Environ. Life Sci., 2(1): 3740.

Vanaraj, P., Saveetha, K., Sankaralingam, A., Rabindram, R. and Robin, S., 2013, variability in Pyricularia oryzae from different rice growing regions of Tamil Nadu, India, Afr. J. Microbiol., 7(26): 3379-3388.

\section{How to cite this article:}

Akhilesh Kumar Kulmitra, Neha Sahu, Mukesh Kumar Sahu, Roshan Kumar, T. Kushram and Sanath Kumar, V.B. 2017. Growth of Rice Blast Fungus Pyricularia oryzae (Cav.) on Different Solid and Liquid Media. Int.J.Curr.Microbiol.App.Sci. 6(6): 1154-1160. doi: https://doi.org/10.20546/ijcmas.2017.606.133 